\title{
AVALIAÇÃO PARASITOLÓGICA DE HORTALIÇAS: DA HORTA AO CONSUMIDOR FINAL
}

\section{Nelciane de Sousa Fernandes Hildeana Rocha Guimarães Ana Clara da Silva Amorim Mouzarllem Barros dos Reis}

Graduados em Biomedicina pela Universidade Federal do Piauí - UFPI, Parnaíba (PI), Brasil

\section{Reginaldo Almeida da Trindade}

Doutor em Biotecnologia pela Universidade de São Paulo - USP, São Paulo (SP), Brasil, Docente Adjunto da Universidade Federal do Rio de Janeiro - UFRJ, Rio de Janeiro (RJ), Brasil

\section{Ana Carolina Fonseca Lindoso Melo}

Doutorado em Ciências Veterinárias pela Universidade Estadual do Ceará - UECE, Fortaleza (CE); Docente Adjunto da Universidade Federal do Ceará - UFC, Faculdade de Medicina, Brasil.

E-mail: acflmelo@gmail.com
RESUMO: Atualmente, o consumo de alimentos in natura tem aumentado devido à busca por uma alimentação mais saudável pela população. Entretanto, a qualidade destes alimentos em relação à sanidade microbiológica é um fator preocupante, pois a ingestão de verduras cruas pode ser um importante meio de transmissão de enteroparasitas. Este estudo avaliou a contaminação parasitária de verduras coletadas e comercializadas em hortas, feiras-livres, supermercados e restaurantes na cidade de Parnaíba, Piauí. Foram analisadas 404 amostras de hortaliças frescas. Destas, 36 foram coletadas em hortas, 120 em feiras-livres, 120 em supermercados locais e 128 em restaurantes (64 amostras pré-manipuladas e 64 pós-manipuladas). As hortaliças foram homogeneizadas com água destilada e submetidas à sedimentação por 24 horas. $\mathrm{O}$ sedimento foi examinado sob microscopia de luz. Foram encontradas contaminações por parasitas em 53\% das amostras de hortaliças com diferenças significativas entre os locais de coleta $(p<0,05)$. Os parasitas Entamoeba coli, Endolimax nana e larvas de Strongyloides spp foram os mais frequentes. A presença de protozoários foi significativamente maior em comparação aos helmintos $(p<0,05)$. O tipo de adubo na plantação, o uso e o tipo de sanitizantes em restaurantes e o armazenamento sob refrigeração foram fatores com influência significativa sobre as taxas de parasitoses encontradas $(p<0,05)$. Houve uma alta taxa de contaminação por parasitas das hortaliças coletadas em hortas, feiraslivres, supermercados e restaurantes do município de Parnaíba, Piauí. $\mathrm{O}$ adubo, o uso de sanitizantes e a forma de armazenamento foram fatores de risco correlacionados com a contaminação.

PALAVRAS-CHAVE: Doenças Transmitidas por Alimentos; Helmintos; Parasitos; Protozoários; Verduras.

\section{PARASITOLOGICAL ASSESSMENT OF VEGETABLES: FROM THE KITCHEN GARDEN TO THE CONSUMER}

\begin{abstract}
Consumption of food in natura is currently on the increase due to a disposition of the population in eating healthier food. However, the quality of this type of food with regard to microbiological quality is doubtful, since eating raw vegetables may transmit enteroparasites. Current analysis evaluates the parasite contamination of vegetables harvested and commercialized in kitchen gardens, fairs, supermarkets and restaurants in the town of Parnaíba PI Brazil. Four hundred and four samples of fresh vegetables were analyzed, of which 36 were harvested from kitchen gardens, 120 from open-air fairs, 120 from local supermarkets and 128 in restaurants (64 were pre-handled food and 64 were post-handled food). Vegetables were homogenized with distilled water and submitted to sedimentation for $24 \mathrm{~h}$. The sediment was analyzed under a light microscope and revealed that $53 \%$
\end{abstract}


of vegetable samples were contaminated at significant degrees according to the collection sites $(p<0.05)$. The most frequent parasites were Entamoeba coli, Endolimax nana and larvae of Strongyloides spp. The number of protozoa was significantly higher when compared to that of helminths $(p<0.05)$. Types of fertilizers, use and type of sanitization in restaurants and storing under refrigeration had a significant influence on the rates of parasites $(p<0.05)$. There was a high contamination rate by parasites in vegetables from kitchen gardens, fairs, supermarkets and restaurants in Parnaíba PI Brazil. Fertilizers, sanitizers and storage modes were risk factors related to contamination.

KEY WORD: Food-Transmitted Diseases; Helminth; Parasites; Protozoa; Vegetables.

\section{INTRODUÇÃO}

Mudanças nos hábitos alimentares dos brasileiros têm sido vistas nos últimos anos, principalmente em relação a uma maior preocupação com o consumo de alimentos in natura por seus conhecidos e reportados benefícios à saúde. Entretanto, pelas características destes alimentos, tal como não ser processado industrialmente, há a possibilidade de contaminação por microrganismos (SILVA et al., 2005; SOARES; CANTOS, 2005), por exemplo, helmintos, protozoários, bactérias e mesmo vírus, sendo os primeiros mais comuns pela capacidade de sobreviverem viáveis em solo e água (VIEIRA et al., 2013).

A contaminação das hortaliças ocorre por diversas formas, mas predominantemente pelo contato da água contaminada com material fecal humano ou animal utilizada na irrigação das hortas, por contaminação do solo com adubo orgânico processado com dejetos fecais ou ainda pela contaminação das mãos de manipuladores de alimentos, causando as DTAs ou doenças transmitidas por alimentos (ADANI; DUTRA, 2011; ARBOS et al., 2010; CARVALHO; NASCIMENTO; RIBEIRO, 2003; SILVA; ANDRADE; STANDFORD, 2005).

Portanto, a verificação laboratorial da sanidade microbiológica das hortaliças torna-se um importante instrumento de controle de transmissão de doenças para o setor da saúde pública, uma vez que fornece dados sobre as condições higiênicas envolvidas na produção, armazenamento, transporte e manuseio desses produtos, identificando os riscos de contaminação e subsidiando medidas corretivas e preventivas para a descontaminação (FERRO; COSTA-CRUZ; BARCELOS, 2012; SILVA; ANDRADE; STANDFORD, 2005).

Alguns estudos demonstram o risco de contaminação por formas transmissiveis de parasitos pelo consumo de hortaliças in natura. Dentre as principais infecções causadas por parasitas presentes nos vegetais pode-se citar: giardíase, amebíase, ascaridíase, teníase, estrongiloidíase, ancilostomíase e esquistossomose (GREGORIO et al., 2012). A alface (Lactuca sativa) está entre as hortaliças in natura mais consumidas no Brasil, em parte ao seu baixo custo, facilidade de cultivo, e outros aspectos relacionados aos efeitos benéficos à saúde atribuídos ao seu consumo por possuírem altos teores de sais minerais, cálcio e vitaminas. A cebolinha (família Aliacea) e o coentro (família Apiacea), que juntos compreendem o popularmente denominado "cheiro-verde" são importantes plantas condimentares utilizadas na culinária brasileira (EMBRAPA, 2014).

Dentro deste contexto, o objetivo dessa pesquisa foi avaliar a presença de contaminação por parasitas em hortaliças comercializadas na cidade de Parnaíba (PI) em diferentes estabelecimentos distribuidores. Além disso, avaliaram-se alguns hábitos sanitários de higienização nos diferentes locais de coleta (hortas, feiras-livres, supermercados, sacolão e restaurantes) para se identificar possíveis fatores de risco para a contaminação destas hortaliças.

\section{METODOLOGIA}

\subsection{LOCAL DE ESTUDO}

O estudo foi realizado na cidade de Parnaíba, município situado na zona litorânea do Estado do Piauí a uma latitude de $2^{\circ} 54^{\prime} 185^{\prime \prime}$ e uma longitude de 41 ${ }^{\circ} 46^{\prime} 37^{\prime \prime}$. Os locais de coletas das hortaliças consistiram em estabelecimentos comerciais fornecedores: 33 de hortas, 52 de feiras-livres, 45 sacolões e supermercados e 64 restaurantes, abrangendo todo o perímetro do munícipio, que possui uma população de aproximadamente $148 \mathrm{mil}$ habitantes, clima tropical quente e úmido (IBGE, 2014). 


\subsection{AMOSTRAGEM}

Foram coletadas 404 unidades de hortaliças no período de agosto de 2011 a setembro de 2013, com amostragem aleatória em período diuturno. Destas, 36 unidades foram coletadas em hortas, $120 \mathrm{em}$ feiras-livres, 120 em supermercados e 128 em restaurantes, sendo 64 coletadas na fase de pré-manipulação e outras 64 coletadas pós-manipulação. Esta manipulação consistiu no uso de sanitizantes, tais como a lavagem com água, solução de cloro, hipoclorito de sódio e vinagre. As amostras foram acondicionadas em sacos de polietileno identificados, e em seguida foram encaminhadas para análise parasitológica no laboratório do Núcleo de Imunoparasitologia Aplicada da Universidade Federal do Piauí no campus de Parnaíba.

\subsection{PROCESSAMENTO E ANÁLISE PARASITOLÓGICA}

Para a análise parasitológica foram utilizados os componentes das hortaliças que são mais passíveis de contaminação por estruturas parasitárias, quer seja por seu contato direto com o solo, quer seja por meio de irrigação com águas contaminadas durante o seu cultivo ou seu manuseio. Para isso, estabeleceram-se as folhas como unidade amostral da alface, e o maço (agrupamento de folhas amarradas) para a cebolinha e o coentro, conforme são comercializados.

As amostras selecionadas foram divididas $\mathrm{e}$ submetidas a lavagem e homogeneização com água destilada em saco plástico descartável por 15 minutos. $\mathrm{O}$ homogenato resultante foi colocado em cálice de sedimentação, e decantado por 24 horas. Após este tempo, o sedimento foi depositado entre lâmina e lamínula e analisado ao microscópio com aumento total de 100 e 400 vezes, de acordo com a metodologia utilizada por Takayanagui et al. (2006).

\subsection{AVALIAÇÃO DOS FATORES DE RISCO}

Os 160 responsáveis pelos estabelecimentos responderam ao questionário com informações higiênicosanitárias, estruturado por um conjunto de questões objetivas e de múltipla escolha.

\subsection{ANÁLISE ESTATÍSTICA}

Trata-se de um estudo epidemiológico de caráter transversal. Os dados foram organizados em tabelas de contingência para avaliar as possíveis associações entre as taxas de parasitoses encontradas e os fatores de risco pesquisados por meio dos questionários aplicados. $\mathrm{O}$ teste exato de Fischer e o teste do chi-quadrado foram aplicados e escolhidos dependendo do tipo de fator de risco avaliado. O nível de significância estatística adotado foi de $5 \%(p \leq 0,05)$

\subsection{CONSIDERAÇÕES ÉTICAS}

Cada responsável pelos estabelecimentos assinou um termo de consentimento livre e esclarecido (TCLE) autorizando a utilização do material coletado para os fins desta pesquisa. Esta pesquisa obteve aprovação pelo Comitê de Ética em Pesquisa da Universidade Federal do Piauí registrado sob $n^{\circ}$ CAAE (Certificado de Apresentação para Apreciação Ética): 0014.0.045.000-09.

\section{RESULTADOS}

A prevalência global de contaminação parasitária nas hortaliças analisadas foi de $53 \%$. As quantidades de amostras de hortaliças contaminadas por local de coleta são mostradas na Figura 1. Houve diferença estatisticamente significativa entre as taxas de parasitoses encontradas nas hortas comparadas às feiras-livres ( $p$-valor $=0,0137)$ e destas comparadas a sacolóes/ supermercados $\quad(p$-valor $=0,0005)$ e restaurantes $(p<0,0001)$. 


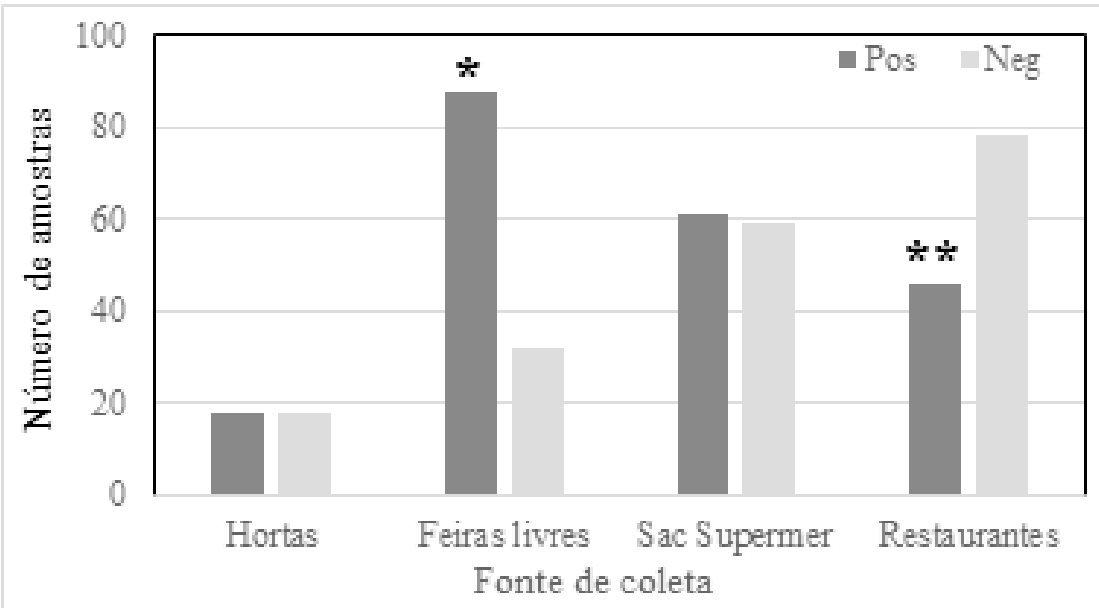

Figura 1. Número de amostras positivas e negativas para parasitas em relação ao local de coleta. (*) Diferença estatisticamente significativa nas comparações Feiras x Hortas $(p=0,013)$, Feiras x Sac/Supermer $(p=0,0005)$ e Feiras x Restaurantes $(p<0,0001)$. ( $* *)$ Diferença estatisticamente significativa nas comparações Sac/Supermer $\mathrm{x}$ Restaurantes $(p=0,038)$.

Das 128 amostras de hortaliças coletadas em restaurantes, 33 que não foram pré-manipuladas com uso de sanitizantes e 18 pós-manipuladas pelo uso de sanitizantes apresentaram contaminação por estruturas parasitárias. Estas diferenças foram estatisticamente significativas $(p=0,011)$. Em relação à manipulação pelo uso de soluções sanitizantes antes das amostras serem coletadas de restaurantes também houve diferença estatisticamente significativa em relação às amostras sem manipulação prévia comparadas às amostras manipuladas ( $p$-valor $<0,0001)$ e também houve diferença significativa em relação ao tipo de sanitizantes utilizado $(p=0,022)$, conforme mostrado nas Figuras 2A e 2B.
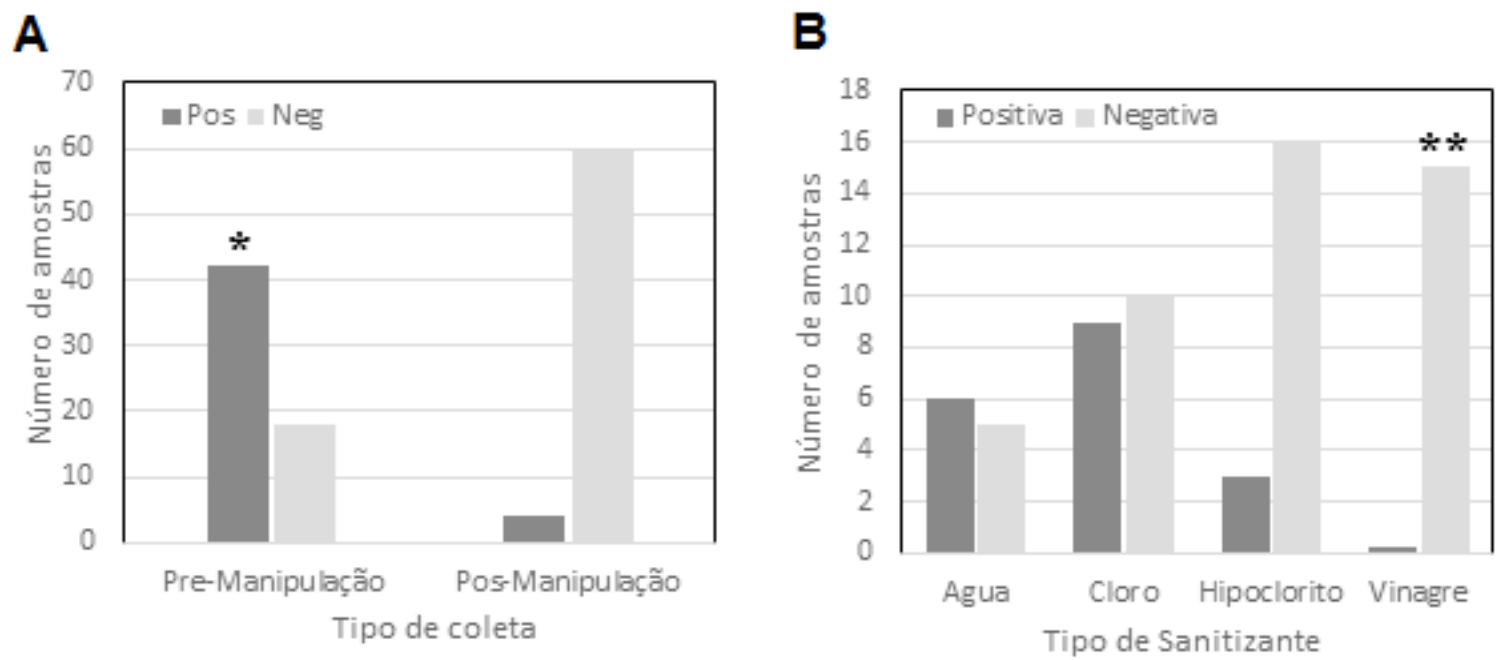

Figura 2. Número de amostras positivas e negativas para parasitas em relação ao (A) uso de sanitizantes e (B) ao tipo de sanitizantes. (*) Diferença estatisticamente significativa nas comparações entre pré-manipulação e pós-manipulação $(p<0,0001)$. ( $\left.{ }^{* *}\right)$ Diferença estatisticamente significativa nas comparações entre os tipos de sanitizantes utilizados $(p=0,0022)$. 
Em relação aos tipos de parasitas encontrados nas hortaliças, houve maior prevalência de protozoários em relação a helmintos. Entamoeba coli foi encontrada em 120 das amostras positivas (56\%), seguida da presença de Endolimax nana em 43 amostras (20\%). Dentre os helmintos, as larvas de Strongyloides ssp foram encontradas em 107 das amostras positivas (50\%). A Figura 3 mostra a distribuição dos tipos de parasitas encontrados por cada fonte de coleta.

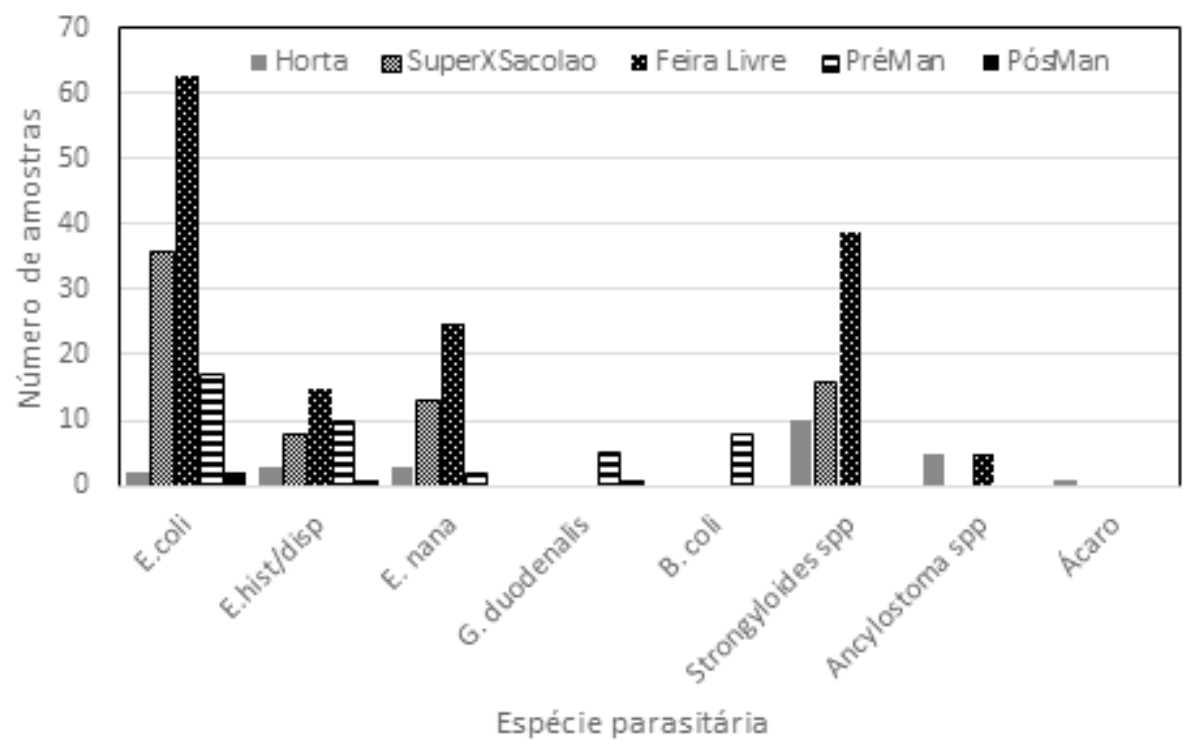

Figura 3. Distribuição de parasitas encontrados nas hortaliças nos diferentes estabelecimentos localizados no município de Parnaíba, Piauí.

Quanto ao tipo de parasita encontrado nas amostras, foi encontrada uma maior presença de protozoários em relação aos helmintos, e nas amostras coletadas em feiras-livres. Esta diferença foi estatisticamente significativa comparada aos demais pontos de coleta $(p=0,0002)$.

Quanto à participação dos manipuladores em cursos de capacitação em "Boas Práticas de Produção", este estudo revelou que $70 \%$ dos manipuladores nunca haviam participado de treinamentos para manipulação de alimentos. Na Tabela 1 são apresentados alguns hábitos higiênico-sanitários relatados por estes indivíduos nos questionários aplicados. As respostas obtidas indicaram o poço como principal fonte de água para irrigação das hortaliças (65\%). Entretanto, a utilização de água de poço não foi um fator estatisticamente significativo sobre as taxas de parasitoses encontradas neste estudo $(p=0,412)$.
Tabela 1. Aspectos relacionados aos hábitos de higiene e quanto ao manuseio de hortaliças, obtidos através de inquéritos em porcentagem de respostas

\begin{tabular}{lcc}
\hline \multicolumn{1}{c}{ Variáveis } & \multicolumn{2}{c}{ Respostas } \\
& $\begin{array}{c}\text { Sim } \\
\text { (\%) }\end{array}$ & $\begin{array}{c}\text { Não } \\
\text { (\%) }\end{array}$ \\
\hline $\begin{array}{l}\text { Curso na preparação de alimentos } \\
\text { Conhecimento de exigências higiênico- }\end{array}$ & 30 & 70 \\
sanitárias & 17 & 83 \\
Utilização de uniformes limpos & 10 & 90 \\
$\begin{array}{l}\text { Higienização adequada das mãos durante } \\
\text { O manuseio }\end{array}$ & 96 & 4 \\
Manipulação de dinheiro & 71 & 29 \\
Utilização de proteções para cabelos & 9 & 91 \\
\hline
\end{tabular}

Foi relatado o uso de diferentes tipos de adubo no cultivo das hortaliças, sendo fezes de aves $(9,2 \%)$, fezes de bovinos $(52,1 \%)$, fezes de caprinos e adubo químico (15\%). A utilização de fezes de bovinos foi predominante entre os horticultores e também a mais associada com a presença de parasitas nas amostras de hortaliças $(p=0,044)$ conforme é mostrado na Figura 4 . 


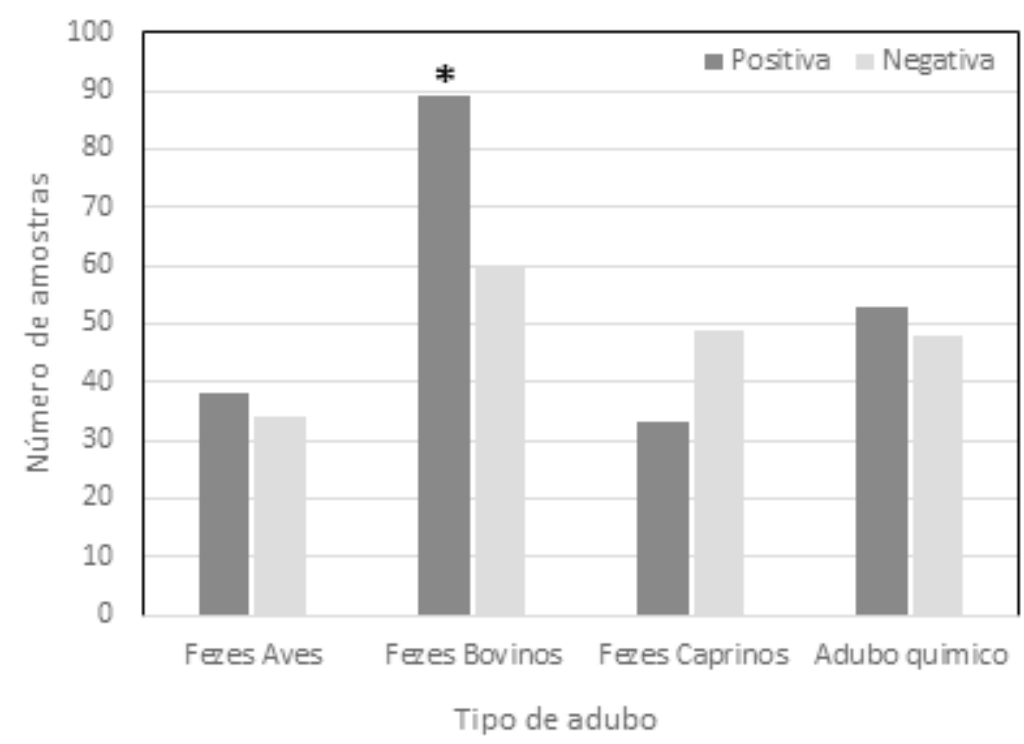

Figura 4. Número de amostras positivas e negativas para parasitas em relação ao tipo de adubo utilizado. $\left(^{*}\right)$ Diferença estatisticamente significativa $(p=0,044)$.

Quanto à forma de armazenamento das hortaliças, $76 \%$ dos responsáveis pelos estabelecimentos afirmaram não utilizar refrigeração. $\mathrm{O}$ uso de refrigeração no armazenamento das hortaliças mostrou ser um fator de risco estatisticamente significativo em relação à presença de parasitas nas amostras $(p<0,0001)$. Em $65,2 \%$ dos casos foi relatado que o principal meio de transporte das hortaliças até estabelecimentos era em veículo aberto, e apenas 6\% dos responsáveis dos restaurantes afirmaram realizar o transporte em veículos fechados e refrigerados.

Em relação ao tempo de trabalho com manipulação de alimentos, $23 \%$ responderam que havia até três anos; 52\% afirmaram trabalhar há um ano; e 25\% por período de até seis meses. O tempo de trabalho ou experiência na manipulação de hortaliças não mostrou ser um fator significativo associado à contaminação encontrada $(p=0,802)$.

\section{DISCUSSÃO}

A elevada contaminação parasitária das hortaliças descrita neste estudo revela condições comuns a muitas outras regiões do país, relatadas em outros estudos similares. O risco de contaminação humana pelo consumo das hortaliças depende, entre outros fatores, da frequência com que os cistos de protozoários e ovos de helmintos aparecem nesses alimentos (TAKAYANAGUI et al., 2007). Segundo Arbos et al. (2010), a principal forma de contaminação de organismos patogênicos em hortaliças ocorre por meio de água contaminada por material fecal humano ou animal utilizada na irrigação artificial das hortas. Outras formas também são relatadas, tais como o contato com dejetos fecais ou animais como aves, moscas, ratos e insetos. Estes últimos, por pousarem sobre fezes depositadas a céu aberto e em seguida sobre os alimentos, são importantes disseminadores mecânicos de parasitas (SLIFKO; SMITH; ROSE, 2000).

A taxa de contaminação parasitária encontrada neste estudo foi superior a de outros trabalhos, como o realizado por Al-Megrin (2010) que encontrou prevalência de $16 \%$ nas amostras analisadas; Parteli e Gonçalves (2005) que encontraram parasitoses em $34 \%$ das amostras analisadas; entretanto, foi inferior ao realizado por Abougrain et al. (2010) que encontraram 58\% de contaminação por helmintos e cistos de protozoários e por Silva, Andrade e Stanford (2005) que encontraram $60 \%$ de positividade em amostras de alface na cidade de Recife (PE). Os resultados de contaminação em hortaliças são sempre discrepantes porque dependem de muitos fatores, tais como a forma de irrigação nas plantações e a forma de manuseio pelos manipuladores, assim os resultados apresentam amplas variações. Por exemplo, em estudo realizado na Índia foi encontrada uma prevalência de 44,2\% dos vegetais contaminados por helmintos (GUPTA; KHAN; SANTRA, 2009), e em outro 
realizado no Sul do Brasil, das 120 amostras de alface analisadas somente uma não apresentou contaminação, resultando em uma taxa de contaminação bastante alta de 99,16\% (COSTANTIN; GELATTI; SANTOS, 2013). Em concordância, outra pesquisa realizada por Neres et al. (2011), na cidade de Anápolis (GO), mostrou 100\% de contaminação parasitária nas 62 amostras de alface crespa de cultivos tradicional e hidropônico, oriundas de diferentes regiões. Estes são dados preocupantes, pois demonstram que as práticas de higienização adequada das hortaliças frequentemente são negligenciadas por produtores ou distribuidores.

As espécies de parasitas mais comumente encontradas neste estudo em ordem decrescente foram Entamoeba coli, Strongyloides spp., Entamoeba histolytica/dispar, Endolimax nana, Ancylostoma spp e Giardia duodenalis. Estes parasitas também foram encontrados em maior prevalência nos resultados relatados por Gregório et al. (2012) e Vieira et al. (2013), ainda que em proporções de protozoários/helmintos diferentes. É possível inferir que alguns destes parasitas são naturalmente mais resistentes à sobrevivência no ambiente, seja em solo, por serem geohelmintos ou em água.

Algumas espécies protozoárias encontradas neste estudo, como Entamoeba coli, são consideradas comensais intestinais e não constituem um agravo à saúde, no entanto, atuam como um forte indicador de contaminação fecal nas amostras analisadas (SANTOS et al., 2009). Por outro lado, a contaminação por Giardia duodenalis pode ocorrer por água contaminada, contaminação ambiental e durante o transporte (MELO et al., 2011; VIEIRA et al., 2013), e trata-se de um parasita que infecta milhares de pessoas em todo o mundo de forma assintomática ou com manifestações clínicas agudas ou crônicas importantes, como diarreia e má absorção de nutrientes (REY, 2011).

A contaminação com Strongyloides spp pode ser consequência da adubação orgânica, uma vez que os produtores relatam a utilização de adubo de esterco bovino. Neste aspecto, Soares e Cantos (2005) têm atribuído ao armazenamento inadequado a ocorrência do estrume contaminado por estes agentes patogênicos. Do mesmo modo, a exposição prolongada das hortaliças, quando em bancadas de venda, em contato direto com o ambiente pode sugerir a contaminação por larvas de Strongyloides spp e Ancylostoma spp, que apresentam formas de resistência para estes locais. Além disso, é provável que após a lavagem, as larvas persistam nas hortaliças devido à sua estrutura e tamanho, que dificulta sua remoção (FALAVIGNA et al., 2005). Santos et al. (2009) têm relatado que em relação aos ovos de ancilostomídeos, muitas plantas e animais possuem parasitas com estruturas similares que eventualmente poderiam superestimar os resultados encontrados apenas por análises microscópicas.

Outros contaminantes encontrados com uma frequência menor, como os ácaros, podem ser explicados pela sua numerosa população nos ambientes em geral. A quantidade de ácaros ambientais é da ordem de milhares, e eles facilmente alcançam os alimentos (SANTOS et al., 2009). Embora estes agentes não estejam diretamente relacionados com as DTAs, a presença de alérgenos derivados de ácaros desempenha um papel importante na patogênese da asma, eczema e da rinite alérgica (FERREIRA et al., 2009).

Inquéritos epidemiológicos que avaliam a relação entre a manipulação inadequada e a contaminação de hortaliças têm sido realizados por outros autores (NOLLA; CANTOS, 2005). De forma semelhante, Melo et al. (2011) já têm demonstrado em estudo no município de Parnaíba que maus hábitos de higiene por manipuladores infectados com enteroparasitos podem contribuir de forma indireta para a contaminação das hortaliças, constituindo um importante veículo de transmissão de parasitos intestinais em humanos.

Apesar de a maioria (83\%) dos respondentes ter relatado que conhecem as práticas básicas de higiene na manipulação de alimentos, as altas taxas de positividade nas análises levam a crer que medidas preventivas importantes possam ter sido negligenciadas por parte dos entrevistados, atuando na manutenção de uma possível exposição constante dos indivíduos às fontes de infecção. De acordo com Tavolaro, Oliveira e Lefévre (2006), para haver modificações efetivas nos hábitos higiênicos dos manipuladores, as formas de intervenção devem considerar também alguns hábitos tradicionais e crenças destes indivíduos. 
Os manipuladores de alimentos na sua grande maioria (70\%) não possuíam treinamento adequado para esta função. A falta do treinamento é expressa pelas seguintes observações: ausência do uso de uniformes, luvas, sapatos fechados ou proteção para os cabelos. A obediência a estas condutas é preconizada pela legislação vigente na RDC $\mathrm{n}^{0} 216$ de 2004 da Agência Nacional de Vigilância Sanitária (ANVISA) (BRASIL, 2004). Além disso, os manipuladores de alimentos devem receber treinamento contínuo quanto à produção, transporte, armazenamento e distribuição dos alimentos, minimizando os riscos de transmissão das enteroparasitoses (STEFANELLO; LINN; MESQUITA, 2009; TAVOLARO; OLIVEIRA; LEFÉVRE, 2006).

$\mathrm{O}$ fato de grande parcela da população não se preocupar com a qualidade da água e não fazer o seu tratamento de forma correta estabelece uma possível vertente na cadeia de transmissão (COURA, 2013; REY, 2011). No Brasil, já foi relatado contaminação de água de torneiras de cozinhas, de poços e de cisternas (OTENIO et al., 2007). Apesar de apresentarem baixas prevalências, estas contaminações são consideradas relevantes, devido ao risco facilitado do homem contaminar-se ao ingerir água ou os alimentos lavados com esta água (LEITE et al., 2011). Neste ponto, é importante ressaltar que muitas vezes somente a filtração não é suficiente para a remoção de alguns parasitos. Por exemplo, Andreatta e Jadoski (2009) observaram que mesmo após a filtração, algumas amostras de água apresentaram-se positivas para cistos de Endolimax nana e A. lumbricoides. Neste caso, a fervura da água pode ser a maneira mais eficiente de eliminar a contaminação por agentes parasitários.

Em relação aos sanitizantes utilizados e relatados neste estudo, é importante ressaltar que a forma de preparação era empírica, sem a utilização de medidas padronizadas. O tempo de exposição das hortaliças a estes sanitizantes variava de minutos a algumas horas. Em alguns casos, a alface era colocada em contato com os sanitizantes no início da manhã e enxaguada em água corrente poucos minutos antes de ser servida. Em relação à eficiência dos tipos de sanitizantes, Adani e Dutra (2011) avaliaram a eficácia do vinagre como sanitizante em alfaces e observaram uma redução no número de microrganismos presentes, porém, não foi eficaz na eliminação, mostrando a necessidade do uso de outros sanitizantes com maior eficiência. No presente estudo não foram observadas contaminações nas amostras processadas com o uso de vinagre. A informação ao consumidor da necessidade de realizar uma higienização adequada também em ambiente domiciliar é muito importante para um consumo seguro (CASTRO, 2013).

Apesar de neste estudo os resultados de correlação entre parasitoses e alguns dos fatores de risco epidemiológicos não terem apresentado significância estatística, exceto para o uso da refrigeração que revelou ter uma relação inversa de dependência com o parasitismo, convém ressaltar que as práticas de higiene pessoal e alimentar ainda são as principais formas preventivas de evitar a contaminação. Em relação ao uso de refrigeração, a relação inversa pode ser explicada pelo fato de que guardar os alimentos na geladeira diminui a proliferação dos microrganismos relacionados às infecções (PORTE; MAIA, 2001).

As hortaliças oriundas de feiras-livres apresentaram uma contaminação significativamente maior em relação aos sacolóes e supermercados, em concordância com resultados relatados por Parteli e Gonçalves (2005); Vieira et al. (2013). Xavier et al. (2009) descrevem duas hipóteses, maior contaminação devido à exposição dos alimentos ao ar livre, sofrendo com alterações biológicas, com manipulação inadequada ou ainda com a poluição urbana, e ainda o hábito de lavar as hortaliças, verduras ou frutas em tanques, o que os deixa sujeitos às contaminações diversas, pois nestes locais a água não é trocada com frequência e os recipientes tornam-se cada vez mais sujos. Por outro lado, a menor contaminação encontrada nas amostras dos restaurantes e supermercados pode ser atribuída a fatores como uma lavagem prévia, uso de sanitizantes, além de nestes ambientes as hortaliças são mais protegidas do contato direto com o ar, solo, dejetos, etc (VIEIRA et al., 2013).

\section{CONCLUSÃO}

Sob as condições experimentais deste estudo, foi possível concluir que existe uma alta prevalência de contaminação por parasitas nas hortaliças comercializadas 
nos estabelecimentos distribuidores de alimentos no município de Parnaíba (PI), principalmente nas feiraslivres. As poucas medidas de sanitização aplicadas por alguns estabelecimentos não se mostraram totalmente eficazes na eliminação da contaminação.

Dentre os principais fatores que possivelmente contribuíram para a presença destes parasitas nas hortaliças, ressaltam-se nesta ordem: a adubação com fezes de animais, a forma de transporte das hortaliças entre a propriedade produtora e o ponto de comercialização, o acondicionamento e manipulação em ambiente não refrigerado e a ausência das boas práticas de higiene em toda a cadeia produtiva.

\section{AGRADECIMENTOS}

À Universidade Federal do Piauí e ao CNPq/ Brasil pelo auxílio financeiro concedido (Processo $\mathrm{n}^{\mathrm{o}}$ 476396/2011-5)

\section{REFERÊNCIAS}

ABOUGRAIN, A. K.; NAHAISHI, M. H.; MADI, N. S.; SAIED, M. M.; GHENGHESH, K. S. Parasitological contamination in salad vegetables in Tripoli-Libya. Food Control, n. 21, p. $760-762,2010$.

ADANI, A. A. V.; DUTRA, M. B. L. Análise da eficácia do vinagre como sanitizante na alface. REAS, v. 3, p. 134144, 2011.

AL-MEGRIN, W. I. Prevalence of intestinal parasites in leafy vegetables in Riyadh, Saudi Arabia. Int J Zool Res, n. 6, p. 137-142, 2010.

ANDREATTA, S. C.; JADOSKI, S. O. Avaliação de metodologia de filtragem para proteção de fontes em locais de risco de contaminação microbiológica da água. Pesqui Apl Agrotec, v. 2, n. 1, p. 69-78, 2009.

ARBOS, K. A.; FREITAS, R. J. S.; STERTZ, S. C.; CARVALHO, L. A. Segurança alimentar de hortaliças orgânicas: sanitários e nutricionais. Ciênc Tecnol Aliment, v. 30, suppl. 1, p. 215-220, 2010.
BRASIL. Agência Nacional de Vigilância Sanitária (ANVISA). Resolução RDC no 216, de 15 de Setembro de 2004. Publicada no Diário Oficial da União, de 16 de Setembro de 2004.

CARVALHO, J. B.; NASCIMENTO, E. R.; RIBEIRO, V. R. Presença de ovos de helmintos em hortaliças fertilizadas com iodo da lagoa de estabilização. Rev Bras Anál Clín, v. 35, n. 2, p. 101-103, 2003.

CASTRO, F. T. Ações de intervenções para promoção do consumo seguro de frutas e hortaliças em pontos de vendas da zona oeste do Rio de Janeiro. Oikos Rev Bras Econ Domést., v. 24, n. 1, p. 004-030, 2013.

COSTANTIN, B. S.; GELATTI, L. C.; SANTOS, O. Avaliação da contaminação parasitológica em alfaces: um estudo no sul do Brasil. Rev Fasem Ciênc, v. 3, p. 9-22, 2013.

\section{COURA, J. R. Dinâmica das doenças infecciosas e} parasitárias. 2. ed. Rio de Janeiro: Guanabara Koogan, 2013.

EMBRAPA. EMPRESA BRASILEIRA DE PESQUISA AGROPECUÁRIA. Hortaliças na Web. Disponível em: <http://www.cnph.embrapa.br/hortalicasnaweb/ index $>$. Acesso em: 28 jun. 2014.

FALAVIGNA, L. M.; FREITAS, C. B. R. F.; MELO, G. C.; NISHI, L.; ARAUJO, S. M.; FALAVIGNA-GUILHERME, A. L. Qualidade de hortaliças comercializadas no noroeste do Paraná, Brasil. Parasitol Latinoam, v. 60, p. 144-149, 2005.

FERREIRA, M. A. S.; RODRIGUES, J. S.; ANDRADE, R. L. F. S.; JESUS, H. A.; BARROS, S. L. B. Avaliação de endoparasitos em cães domiciliados, de abrigo e errantes na cidade de Aracaju-SE. Medicina Veterinária, v. 3, p. 20-25, 2009.

FERRO, J. J. B.; COSTA-CRUZ, J. M.; BARCELOS, I. S. Avaliação parasitológica de alfaces (lactuca sativa) comercializadas no município de Tangará da Serra, Mato Grosso, Brasil. Rev Patol Tropical, v. 41, p. 47-54, 2012. 
GREGÓRIO, D. S.; MORAES, G. F. A.; NASSIF, J. M.; ALVES, M. R. M.; CARMO, N. E.; JARROUGE, M. G. Estudo da contaminação por parasitas em hortaliças da região leste de São Paulo. Science in Health, v. 3, p. 96-103, 2012.

GUPTA, N.; KHAN, D. K.; SANTRA, S. C. Prevalence of intestinal helminth eggs on vegetables grown in wastewater-irrigated areas of Titagarh, West Bengal, India. Food Control, v. 20, p. 942-945, 2009.

IBGE. INSTITUTO BRASILEIRO DE GEOGRAFIA E ESTATÍSTICA. Censo Populacional de Parnaíba-PI, 2010. Disponível em: <http://www.ibge.gov.br/> Acesso em: 28 maio 2014.

LEITE, L. C.; CIRIO, S. M.; ZADOROSNEI, A. C. B.; LEITE, S. C.; LEITE, M. C.; BENIN, L. A. Avaliação da contaminação ambiental por ovos de Ancylostoma spp. em logradouros públicos de Curitiba - Paraná - Brasil. Ambiência, v. 7, p. 295-303, 2011.

MELO, A. C. F. L.; FURTADO, L. F. V.; FERRO, T. C.; BEZERRA, K. C.; COSTA, D. C. A.; COSTA, L. A. Contaminação parasitária de alfaces e sua relação com enteroparasitoses em manipuladores de alimentos. $\mathbf{R}$ Tróp: Ci Agr Biol, n. 5, n. 3, p. 47-52, 2011.

NERES, A. C.; NASCIMENTO, A. H.; LEMOS, K. R. M.; RIBEIRO, E. L.; LEITÃO, V. O.; PACHECO, J. B. P. Enteroparasitos em amostras de alface (Lactuca Sativa Var. Crispa), no município de Anápolis, Goiás, Brasil. Biosci J, v. 27, n. 2, p. 336-341, 2011.

NOLLA, A. C.; CANTOS, G. A. Relação entre a ocorrência de enteroparasitoses em manipuladores de alimentos e aspectos epidemiológicos em Florianópolis, Santa Catarina, Brasil. Cad Saúde Pública, v. 21, n. 2, p. 641645, 2005.

OTENIO, M. H.; TOMÉ, M. C. C.; CHIES, B. P.; CLARO, E. M. T.; OLIVEIRA, I. P.; RAVAGNANI, C. Saneamento básico, qualidade de água e levantamento de enteroparasitas relacionando ao perfil Sócio-Econômico-Ambiental de escolares de uma área rural do município de BandeirantesPR. Salusvita, v. 26, n. 2, p. 179-188, 2007.

PARTELI, D. P.; GONÇALVES, S. A. Pesquisa de parasitas intestinais em folhas de alfaces (Lactuca Sativa $\mathrm{L}$.) comercializadas no município de Vitória-ES. 2005. Monografia (Trabalho de Conclusão de Curso) - Faculdade de Farmácia, Faculdade Brasileira - Univix, 2005.

PORTE, A.; MAIA, L. H. Alterações fisiológicas, bioquímicas e microbiológicas de alimentos minimamente processados. Boletim do CEPPA, n. 19, p. 105-118, 2001.

REY, L. Bases da parasitologia médica. 3. ed. Rio de Janeiro: Guanabara Koogan, 2011.

SANTOS, N. M.; SALES, E. M.; SANTOS, A. B.; DAMASCENO, K. A.; THÉ, T. S. Avaliação parasitológica de hortaliças comercializadas em supermercados e feiras livres no município de Salvador/BA. Rev Ci Méd Biol, v. 8, p. 146-152, 2009.

SILVA, C. G. M. S.; ANDRADE, S. A. C.; STANFORD, T. L. M. Ocorrência de Cryptosporidium spp e outros parasitos em hortaliças consumidas in natura no Recife. Ciênc Saúde Coletiva, v. 10, p. 63-69, 2005.

SILVA, J. O.; CAPUANO, D. M.; TAKAYANAGUI, O. M.; GIACOMETTI, E. J. Enteroparasitoses e onicomicoses em manipuladores de alimentos do município de Ribeirão Preto, São Paulo, Brasil. Rev Bras Epidemiol, v. 8, p. 385-392, 2005.

SLIFKO, T. R.; SMITH, H. V.; ROSE, J. B. Emerging parasite zoonoses associated with water and food. Int $\mathbf{J}$ of Parasitol, v. 30, p. 1379-1393, 2000.

SOARES, B.; CANTOS, G. A. Qualidade parasitológica e condições higiênico-sanitárias de hortaliças comercializadas na cidade de Florianópolis, Santa Catarina, Brasil. Rev Bras Epidemiol, v. 8, p. 377-384, 2005.

STEFANELLO, C. L.; LINN, D. S.; MESQUITA, M. O. Percepção sobre boas práticas por cozinheiras e auxiliares de cozinha de uma UAN do nordeste do Rio Grande do Sul. Vivências, v. 5, p. 93-98, 2009.

TAKAYANAGUI, O. M.; CAPUANO, D. M.; OLIVEIRA, C. A. D.; BERGAMINI, A. M. M.; OKINO, M. H. T.; CASTRO E SILVA, A. A. M. C. Análise da cadeia de produção de 
verduras em Ribeirão Preto, SP. Rev Soc Bras Med Trop, v. 39, p. 224-226, 2006.

TAKAYANAGUI, O. M.; CAPUANO, D. M.; OLIVEIRA, C. A. D.; BERGAMINI, A. M. M.; OKINO, M. H. T.; CASTRO E SILVA, A. A. M. C. Avaliação da contaminação de hortas produtoras de verduras após a implantação do sistema de fiscalização em Ribeirão Preto, SP. Rev Soc Bras Med Trop, v. 40, p. 239-241, 2007.

TAVOLARO, P.; OLIVEIRA, C. A. F.; LEFÉVRE, F. Avaliação do conhecimento em práticas de higiene: uma abordagem qualitativa. Interface, v. 10, p. 243-254, 2006.

VIEIRA, J. N.; PEREIRA, C. P.; BASTOS, C. G. G.; NAGEL, A. S.; ANTUNES, L.; VILLELA, M. M. Parasitos em hortaliças comercializadas no sul do Rio Grande Do Sul, Brasil. Rev Ciênc Méd Biol, v. 12, n. 1, p. 33-38, 2013.

XAVIER, A. Z. P.; VIEIRA, G. D. G.; RODRIGUES, L. O. M.; VAlVERDE, L. O.; PEREIRA, V. S. Condições higiênico-sanitárias das feiras-livres do município de Governador Valadares. 2009. Monografia (Trabalho de Conclusão de Curso) - Universidade Vale do Rio Doce, Governador Valadares, 2009.

Recebido em: 03 de junbo de 2015 Aceito em: 24 de agosto de 2015 